This manuscript is a preprint and has been accepted for publication in Geophysical Research Letters. The final version of this manuscript is available via the 'Peer-reviewed Publication DOI' link on the right-hand side of this webpage. Please feel free to contact any of the authors; we welcome feedback.

\title{
Fluid surface coverage showing the controls of rock mineralogy on the wetting state
}

\author{
Gaetano Garfi ${ }^{1}$, Cédric M. John ${ }^{1}$, Qingyang Lin ${ }^{1}$, Steffen Berg ${ }^{1,2}$, Samuel \\ Krevor $^{1}$ \\ ${ }^{1}$ Imperial College London, Department of Earth Science and Engineering, London, UK \\ ${ }^{2}$ Shell Global Solutions International B.V., Amsterdam, The Netherlands and Imperial College London, \\ Department of Earth Sciences and Engineering, Department of Chemical Engineering, London, UK
}

\section{Key Points:}

- The analysis of fluid surface coverage is proposed as a novel approach to rock wettability characterisation

- A thermodynamically constrained model is derived and tested on a Bentheimer sandstone water-wet X-ray micro-CT dataset

- In a Berea sandstone, fluid surface coverage shows that rock mineralogy controls system local wettability after exposure to crude oil

Corresponding author: Gaetano Garfi,g.garfi17@imperial.ac.uk 


\begin{abstract}
The wetting state is an important control on flow in subsurface multi fluid phase systems, e.g., carbon storage and oil production. Advances in X-ray imaging allow us to characterise the wetting state using imagery of fluid arrangement within the pores of rocks. We derived a model from equilibrium thermodynamics relating fluid coverage of rock surfaces to wettability and fluid saturation. The model reproduces the behaviour measured in a water-wet, nearly all-quartz, Bentheimer sandstone imaged during steady-state imbibition. A shift in fluid surface coverage is observed when the rock is altered to a new wetting state with crude oil. In two multi-mineralogical (Berea) samples, one water-wet and the other altered with crude oil, the analysis of fluid surface coverage after imbibition revealed mineral specific wetting preferences only in the altered system. Clays and calcite preferentially alter to an oil-wet state, leading to mixed wettability in the rock.
\end{abstract}

\title{
Plain Language Summary
}

The movement of multiple fluid phases through the pores of rocks is central to many processes of scientific and societal interest, e.g., $\mathrm{CO}_{2}$ storage, oil production. When two or more fluids occupies rock pores, the way these fluids move strongly depends on the way the fluids interact with the mineral surfaces constituting rock pore walls. In general, the mineral surfaces prefer to be in contact with one particular fluid. This wetting preference controls the flow of these fluids across large scales in the subsurface.

In this work, we proposed a theoretical and practical approach to characterise this wetting preference. Our approach is based on the analysis of the interfaces shared by rock surfaces with each fluid. The extent of these interfaces depends on rock grains wetting preference. Since this preference can be modified by exposing certain rock samples to crude oil, we prove that the fluid-rock interfaces change accordingly in a rock constituted by a single mineralogy. Finally, we investigate mineral wetting preference, in a rock comprising multiple minerals. When previously exposed to crude oil, these minerals show a different wetting preference. This behaviour is not observed when a sample of the same kind was not exposed to crude oil.

\section{Introduction}

Wettability is an important control in subsurface fluid flow, where fluids move through pore networks where capillary forces are dominant (Zou et al., 2018; Rücker et al., 2019; Lin, Bijeljic, Berg, et al., 2019). During oil recovery rock wettability exerts a control on the capillary entry pressure during primary drainage or in determining the likelihood of snap-off events of the non-wetting phase during waterflooding (Blunt et al., 2002). As a consequence of pore scale fluid dynamics, the behaviours of continuum scale properties such as relative permeability and capillary pressure are controlled by the wetting state (Anderson, 1987a, 1987b).

Predicting and characterising the wettability of a reservoir is a complex task. Minerals constituting rocks are naturally water-wet in the absence of hydrocarbon deposits. However, many oil reservoirs show relative permeability and capillary pressure functions indicative of intermediate-wet, mixed-wet or oil-wet systems (Donaldson et al., 1969). Indeed, rock surface wetting preference may be altered by the interaction of the solid substrate with surface-active compounds present in the crude oil. If present, these compounds can precipitate or diffuse to the solid surface and be adsorbed modifying the local wetting state (J. S. Buckley \& Liu, 1998; J. S. Buckley, 1998). The results of these alteration mechanisms are dependent on the thermodynamic conditions, crude oil composition, brine composition and solid surface chemistry. 
A number of studies have characterised the wetting behaviour of minerals typically found in the subsurface, i.e., in carbonate and sandstone reservoirs. A summary of the results of a collection of studies can be found in J. S. Buckley (1998). Calcite and clay minerals have been found to be more responsive to wettability alteration by crude oil exposure than quartz (Alipour Tabrizy et al., 2011). However, experiments on chemically homogeneous flat surfaces or powders can only reproduce uniform altered wettability in the system considered. In order to investigate the role of rock textural complexity, petrography and mineralogical heterogeneity in determining the in situ wetting state, it is necessary to study three-dimensional samples.

$\mathrm{X}$-ray micro-CT offers the opportunity to investigate fluid arrangement inside rock pores (Bultreys, Boone, et al., 2016; Bultreys, De Boever, \& Cnudde, 2016; Coles et al., 1996). With this newfound capability, thermodynamic theory indicates that it should be possible to observe wetting signals from in situ contact angles, interfacial fluid curvature and fluid-solid surface coverage (Morrow \& Szabo, 1970). In situ contact angles have been measured - either manually (Andrew et al., 2014; Singh et al., 2016) or automatically (Klise et al., 2016; Scanziani et al., 2017; AlRatrout et al., 2017) - in the pore space of various rock samples identifying different wetting states (Rücker et al., 2019; Alhammadi et al., 2017). However, the measurements typically obtained have shown a large variability in space and sensitivity to the processing pipeline chosen (Garfi et al., 2019), making their direct employment difficult. Mean interfacial fluid curvature has successfully been employed to map capillary pressure in water-wet and intermediate-wet rock samples (Herring et al., 2017; Garing et al., 2017; Lin et al., 2018a; Lin, Bijeljic, Berg, et al., 2019). However, the interpretation of mean interfacial curvature as a signal of wetting is not straightforward: when the system is not water-wet, interfaces tend to have null mean curvature, meaning that their curvature has opposite sign along the two principal radii of curvature (Lin, Bijeljic, Berg, et al., 2019). The fluid-solid surface coverage is investigated in this study. The measurement of fluid-solid interfacial area benefits from a larger signal (more pixels in the imagery) than the contact angle. It also allows a more direct interpretation than measurements of both contact angle and fluidfluid interfacial curvature (Garfi et al., 2019).

In this study, we show that the characterisation of fluid coverage of rock mineral surfaces can depict changes in the local wetting state. We develop and validate a model, based in the equilibrium thermodynamics of fluid-solid interfaces of a water-wet system, to demonstrate the applicability of solid surface coverage as a measure of wetting. Fluidsolid interfacial areas are then measured to characterise the wetting state of two rock lithologies. We first make use of observations on a mono-mineralogical rock (Bentheimer sandstone) as a case study to test the approach. We then extend our approach to the mineralogically heterogeneous Berea sandstone. We investigate mineral specific wettability in two Berea sandstone samples - one in its original state and one exposed to crude oil to alter the natural mineral wetting preference - by performing two drainage-waterflooding cycle experiments and comparing the fluid arrangement observed in the two images acquired after waterflooding.

\section{Materials and Methods}

\subsection{Mono-mineralogical system: Bentheimer sandstone datasets}

In this work we first make use of two datasets created by Lin et al. (2018a) and Lin, Bijeljic, Berg, et al. (2019) as a case study with a simplified mineralogy. Bentheimer sandstone is $98 \mathrm{wt} \%$ quartz, $1 \mathrm{wt} \%$ kaolinite/chlorite and $1 \mathrm{wt} \%$ microcline, but for the purposes of this work it was assumed to be a homogeneous rock constituted of a single mineralogy. All the images were segmented into rock, brine and oil phases (Lin et al., 2018a; Lin, Bijeljic, Berg, et al., 2019). In our study the region of interest used in the analy- 
sis was $900 \times 900 \times 3000$ voxels with $3.58 \mu m$ voxel side, i.e. the spatial domain analysed was $3.22 \times 3.22 \times 10.74 \mathrm{~mm}^{3}$.

The first dataset - that we call Bentheimer Unaltered - consisted of the X-ray microCT images acquired with two-fluid injection at five fractional flows $\left(f_{w}=q_{w} /\left(q_{w}+\right.\right.$ $q_{o}$ ) where $q_{i}$ are volume flow rates of brine and oil) (S. Buckley \& Leverett, 1942) of the wetting phase, brine phase $\left(f_{w}=\{0.15,0.30,0.50,0.85,1\}\right)$, during steady-state imbibition (brine fractional flow increasing with each step). The fluids in the system were brine (3.5 wt\% KI) and decalin. The initial oil saturation after drainage was $86 \%$. For further information see Lin et al. (2018a).

The second dataset - that we call Bentheimer Altered - used a sample that was very similar to the Bentheimer Unaltered, except that the wetting state was altered before the coreflood. Prior to the flow experiments, this sample was partially saturated with crude oil and heated at $80^{\circ} \mathrm{C}$ for 30 days in a wetting alteration process known as ageing. The fluids in this case were brine $\left(3.5 \mathrm{wt} \% \mathrm{KI}, 1.09 \mathrm{wt} \% \mathrm{NaCl}, 0.02 \mathrm{wt} \% \mathrm{MgCl}_{2} \cdot 6 \mathrm{H}_{2} \mathrm{O}\right.$, $0.11 \mathrm{wt} \% \mathrm{CaCl}_{2} .2 \mathrm{H}_{2} \mathrm{O}$ ) and decalin (Lin, Bijeljic, Berg, et al., 2019; Lin, Bijeljic, Krevor, et al., 2019). Five images at fractional flow steps $f_{w}=\{0.24,0.50,0.80,0.90,1\}$ were considered in this study. The initial oil saturation after drainage was $85 \%$.

\subsection{Multi-mineralogical system: experiments on Berea sandstone}

\subsubsection{Rock samples}

Two Berea sandstone samples of $4 \mathrm{~mm}$ in diameter and $20 \mathrm{~mm}$ in length were drilled from the same core. This core has laminations of cemented calcite. The main mineral groups present were identified by scanning electron microscopy (SEM) operated in back scattered electron (BSE) mode and coupled with energy-dispersive X-ray spectroscopy (EDS) (Lai et al., 2015). Quartz grains constitute the majority of the rock matrix. The other mineral groups identified were clay group minerals (kaolinite, illite and smectite), sodium and potassium feldspars and small traces of minerals embedding metals. As with the Bentheimer, one of the samples was used unaltered by crude oil and is referred to as Berea Unaltered. The other sample underwent crude oil exposure after primary drainage and will be referred to as Berea Altered.

\subsubsection{Fluids, fluid injection strategy, and wettability alteration}

Two drainage-imbibition cycle experiments were performed. In the experiment involving Berea Unaltered, the fluids employed were brine $(15 \mathrm{wt} \% \mathrm{KI}$ in de-ionized water) and decane. The sample was firstly saturated with brine at atmospheric pressure and then pressurized at the injection pressure of 3.5 MPa. Decane was thus injected at a flow rate of $0.015 \frac{\mathrm{ml}}{\mathrm{min}}$, which corresponds to a capillary number $N_{c} \approx 10^{-7}$. The total injected volume of decane was $2.5 \mathrm{ml}$. The initial oil saturation after drainage was larger than $95 \%$. The injection was stopped for at least 4 hours in addition to the scanning time, before performing brine injection. 40 pore volumes were injected at a constant flow rate of $0.015 \frac{\mathrm{ml}}{\mathrm{min}}$.

In the experiment with the sample Berea Altered, the fluids employed were brine (15 wt\% KI, 1.09 wt\% NaCl, 0.02 wt $\% \mathrm{MgCl}_{2} .6 \mathrm{H}_{2} \mathrm{O}, 0.11 \mathrm{wt} \% \mathrm{CaCl}_{2} .2 \mathrm{H}_{2} \mathrm{O}$ ) and an asian degassed crude oil with a density of $0.8592 \mathrm{~kg} / \mathrm{m}^{3}$ and viscosity $9.4672 \mathrm{mPas}$. The crude has a total acid number (TAN) of $0.09 \mathrm{mgKOH} / \mathrm{g}$ and a total basic nitrogen (TBN) of $270.6 \mathrm{mg} / \mathrm{kg}$. The SARA (Saturates, Aromatics, Resing and Asphaltenes) analysis data is Sat $=44.00 \mathrm{wt} \%$, Aro $=44.00 \mathrm{wt} \%$, Res $=9.69 \mathrm{wt} \%$ and Asp $=2.31 \mathrm{wt} \%$.

The sample was firstly saturated with brine. Crude oil drainage was then performed by setting a constant pressure gradient of $5 \mathrm{Mpa}$ between the injection and the receiving pumps, up to a total volume injection of $2.5 \mathrm{ml}$. The initial oil saturation was larger 
than 95\%. After drainage, the sample was then removed from the coreholder and stored immersed in crude oil in a sealed glass bottle. The glass bottle was put into an oven at a temperature of $80^{\circ} \mathrm{C}$ for 30 days. After the wettability alteration protocol, the sample was mounted in the coreholder and waterflooding was performed, by injecting 40 pore volumes of brine at a constant flow rate of $0.015 \frac{\mathrm{ml}}{\mathrm{min}}$.

In both the experiments, after waterflooding the injection was stopped and the system was allowed to equilibrate for 4 hours to a pressure of $3.5 \mathrm{MPa}$.

\subsubsection{Imaging and Image processing of Berea sandstone: minerals and fluids phase segmentation}

The samples were imaged with an FEI Heliscan microCT obtaining a voxel size of $2.0 \mu \mathrm{m}$ for a region of interest larger than the sample cross section and a vertical length of $8 \mathrm{~mm}$. The projections were acquired while the sample was moving along a helical trajectory and a $1 \mathrm{~mm}$ thick aluminium filter was employed. The X-ray source voltage was set to $95 \mathrm{kV}$ and the tube current to $70 \mathrm{~mA}$. The raw images were reconstructed employing an iterative back-projection algorithms provided by the scanner manufacturer. For both samples, images were acquired before the injection of any fluid (referred to as the dry scan) and after waterflooding.

The processing steps were the same for both samples. We filtered the dry scan and waterflooding image by non-local means filtering (Buades et al., 2005) and registered them. The greyscale dry scans were segmented using watershed segmentation (Beucher \& Meyer, 1993) into five phases: pore space, clay group minerals, quartz and feldspar group minerals (that we refer to as quartz-feldspar), cemented calcite and others highly attenuating minerals. The filtered waterflooding image was masked with the segmented pore space image, leading us to the segmentation of the two fluid phases (oil phase and brine phase) by simple thresholding. The region of interest of our analysis for each image was a cube of 1200 voxel side, i.e. $2.4 \mathrm{~mm}$.

\subsection{Rock surface coverage as a measure of wetting: a model for water- wet systems}

Consider a porous medium comprising two fluid phases, a wetting phase, $w$, and a non-wetting phase, $o$, e.g., oil, and a solid phase, $s$. Per unit volume of pore space, the reversible work required to increase the saturation of a non-wetting phase results in the creation of fluid-fluid interfaces, between wetting phase, non-wetting phase, and the solid (Morrow \& Szabo, 1970; Bradford \& Leij, 1997),

$$
P_{c} \mathrm{~d} S_{o}=\sigma_{o w} \mathrm{~d} A_{o w}+\sigma_{o s} \mathrm{~d} A_{o s}+\sigma_{w s} \mathrm{~d} A_{w s}
$$

$P_{c}$ is the capillary pressure, $S_{i}$ is the saturation with $S_{o}=1-S_{w}, \sigma_{i j}$ is the interfacial tension between fluid or solid phase $i$ and phase $j$, and $A$ is the interfacial area per unit volume of pore space between phases.

The use of reversible work in the analysis is equivalent to limiting our consideration to equilibrium states of the system, i.e., $P_{c}\left(S_{o}\right)$ and $A_{i j}\left(S_{o}\right)$ at equilibrium. We ignore irreversible work that may be required in practice to move from one state to the next, e.g., due to transient processes (Berg et al., 2013; Morrow \& Szabo, 1970). This is the assumption made when making use of capillary pressure characteristic curves as constitutive laws in the description of subsurface flow.

By integrating Eq.1, followed by algebraic operations and making use of the Laplace relationship, $P_{c}=2 \kappa \sigma_{o w}$, where $\kappa$ is the mean interfacial curvature of the oil-brine interface, it is possible to derive the following (see the Supporting Information for a full 
derivation):

$$
A_{o s}\left(S_{o}\right)=\frac{1}{\beta} \frac{\sigma_{o w}}{\sigma_{o s}-\sigma_{w s}}\left(2 \int_{S^{\prime}=0}^{S_{o}} \kappa \mathrm{d} S^{\prime}-\int_{S^{\prime}=0}^{S_{o}} \frac{\mathrm{d} A_{o w}}{\mathrm{~d} S^{\prime}} \mathrm{d} S^{\prime}\right)
$$

The terms inside the brackets represent the reversible work of desaturation and the creation of oil-water interfacial area, respectively. The equation expresses the oil-solid interfacial area created from the excess energy available when subtracting the work required for the creation of fluid-fluid interfacial area from the work performed to increase the saturation of the non-wetting phase in the rock. The ratio of interfacial tensions, $\frac{\sigma_{o w}}{\sigma_{o s}-\sigma_{w s}}$, is equivalent to $\frac{1}{\cos \theta}$ in a single capillary tube ( $\theta$ is the contact angle). Without changing sign entirely, the more wetting the solid is with respect to the non-wetting phase (the smaller the value of $\sigma_{o s}$ ), the more interfacial area between the non-wetting phase and solid, $A_{o s}$, will be created per unit of work. The parameter $\beta$ represents a roughness factor that accounts for the mismatch between the real surface area shared by each fluid and the solid surface and the one measurable by imaging, due to imaging resolution limit (Helgeson et al., 1984; White \& Peterson, 1990).

\subsection{Rock surface coverage characterisation by micro-CT imaging}

In order to characterise rock surface coverage, the interfaces between mineral phases and fluid phases were identified. In the case of the Bentheimer datasets two groups of interfaces were identified, between oil and rock, and between brine and rock phases. In the case of the multi-mineral Berea sandstone, having produced segmented images with four mineral phases and two fluids, we identified a total of eight interface groups, i.e., for each mineral and both fluid phases. Once an interface of interest was identified, a smooth surface was constructed through that interface by means of a generalized marching cubes algorithm.

We compare fluid surface coverage of different minerals by defining the fraction of the total area of that mineral in contact with a fluid:

$$
a_{i j}=\frac{A_{i j}}{\sum_{i} A_{i j}}
$$

where $A_{i j}$ is the measured surface area per unit of pore volume shared by fluid $i$ with solid $j$, respectively. The fractional definition of this property serves two purposes: to allow for the comparison of the specific wetting preference of different mineral groups with different total mineral-to-pore surface areas; to make the measurement more robust to the surface smoothing and to the image processing pipeline chosen.

\section{Results and Discussion}

\subsection{Bentheimer sandstone: fluid coverage of chemically homogeneous rock surfaces}

The region of interest for the ten images considered (five for Bentheimer Unaltered and five for Bentheimer Altered) was divided into 90 cubic subvolumes of 300 voxels per side (voxel size $3.58 \mu \mathrm{m}$ ). This allowed us to obtain a topological description of the wetting state of the system investigated. In each of the subvolumes, for each of the images and each of the datasets, fluid saturations, rock volume and fluid-coated interfacial areas were computed.

The results obtained from the employment of our approach to wettability characterisation reconciled well with the authors' assumptions that Bentheimer Unaltered was water-wet (Lin et al., 2018a) and Bentheimer Altered was intermediate or mixed wetting to oil (Lin, Bijeljic, Berg, et al., 2019). Specific oil-rock interfacial area measurements are reported as a function of saturation for each of the subvolumes and for each of the 


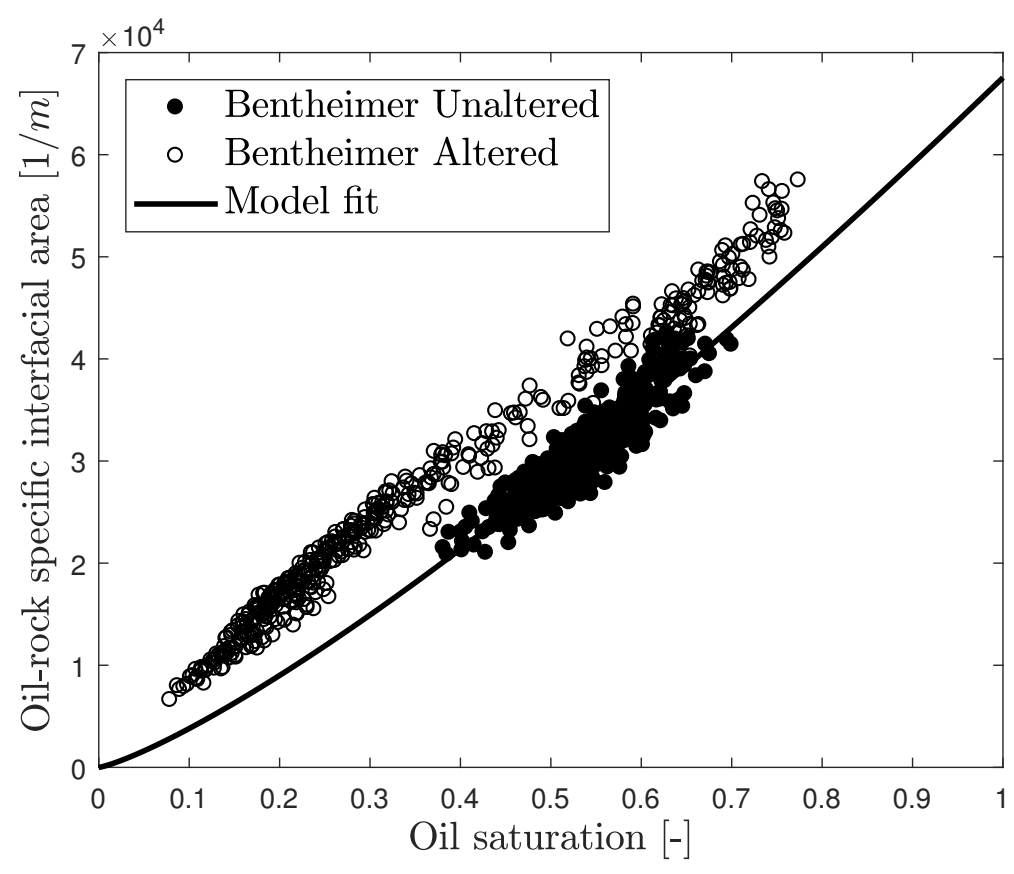

Figure 1. Oil-rock specific interfacial area measured in two Bentheimer sandstone datasets consisting of the X-ray micro-CT images of two steady-state imbibition experiments. For similar oil saturation values, the oil-coated specific interfacial areas are larger in the altered sample than in the unaltered one. The behaviour of the experimental data defined for Bentheimer Unaltered is reproduced by the model (Eq.2). For the details of the fitting process and the input parameters values, see the Supporting Information. The average oil-rock specific interfacial area and fluid saturation measured for each fractional flow considered are available in Table S1 (Supporting Information).

fractional flow considered in the two datasets Bentheimer Unaltered and Bentheimer Altered in Figure 1. For similar oil saturation values, in the intermediate-wet sample (Bentheimer Altered) rock surface coverage by oil is larger. As expected in a mixed or intermediate wet system, oil is more likely to coat the solid surface than in a water-wet system. Figure 1 also shows that the model we proposed for water-wet systems (Eq.2) well reproduces the behaviour of the measured specific oil-rock interfacial area datapoints in the Bentheimer Unaltered dataset. By fitting the model to the experimental data, we estimated $\frac{1}{\beta} \frac{\sigma_{o w}}{\sigma_{o s}-\sigma_{w s}}=0.07$. For a water-wet system $\frac{\sigma_{o w}}{\sigma_{o s}-\sigma_{w s}} \geq 1$. This implies that the geometrical roughness factor $\beta \approx 10^{0}-10^{3}$, consistent with literature roughness factor values defined by comparing surface areas measured with BET to those estimated by X-ray micro-CT imaging for other sandstone rocks (Lai et al., 2015). For additional information on model fitting and the choice of input parameters, refer to the Supporting Information, where we also refer to Joekar-Niasar and Hassanizadeh (2012), Porter et al. (2009) and Raeesi et al. (2014).

\subsection{Berea sandstone: the role of rock surface mineralogy in controlling the wetting state}

In this case the region of interest was divided as the previous case in cubic subvolumes of 300 voxels side, for a total of 64 subvolumes. In each of the subvolumes fluid saturations, mineral volume fractions and specific mineral fluid coating were computed. 
Table 1. Mineral volumetric composition and remaining fluid saturation (oil remaining saturation $S_{o r}$, brine remaining saturation $S_{w r}$ ) after waterflooding from X-ray micro-CT images of the two Berea samples used in this study: Berea Unaltered (not aged by crude oil exposure) and Berea Altered (aged by crude oil exposure). The images were segmented into six phases: clay group minerals, quartz and feldspar (named quartz-feldspar phase), calcite cementation, other highly X-ray attenuating minerals, oil phase and brine phases.

$\begin{array}{ccccc} & \text { Berea Unaltered } & & \text { Berea Altered } \\ \text { Mean [-] } & \text { St.Dev [-] } & \text { Mean [-] } & \text { St.Dev [-] } \\ \text { Clay } & 0.040 & 0.009 & 0.045 & 0.010 \\ \text { Quartz-Feldspar } & 0.840 & 0.046 & 0.813 & 0.043 \\ \text { Calcite } & 0.115 & 0.050 & 0.135 & 0.048 \\ \text { Others } & 0.006 & 0.004 & 0.006 & 0.004 \\ S_{\text {or }} & 0.572 & 0.050 & 0.239 & 0.071 \\ S_{w r} & 0.428 & 0.050 & 0.761 & 0.071\end{array}$

\subsubsection{Mineral composition and fluid saturation}

The segmentation of the images of the two Berea sandstone samples led to similar mineral compositions (Table 1). This confirmed that the mineral segmentation workflow employed is reproducible. The largest component of the rock matrix is the quartzfeldspar group minerals. Cemented calcite constitutes the second most abundant mineral by volume fraction in the samples. Due to the process through which this cementation likely formed, it is pore filling, exposing mineral surfaces only to poorly accessible regions of the pore space. Segmented clay group minerals are broadly distributed, either as patches on quartz and feldspar grains or as clay aggregates.

The injection of 40 pore volumes of brine led to distinct values of remaining fluid saturation between the unaltered and the altered samples. Berea Unaltered shows an average remaining oil saturation of $57 \%$, while in Berea Altered oil displacement was more effective, leading to an average oil saturation of only $24 \%$. Mixed-wet conditions are more favourable to the recovery of the oil phase as it has been observed extensively on larger coreflood tests (Salathiel, 1973). As observed for the Bentheimer datasets, the variability in saturation is larger for the sample that underwent the wettability alteration procedure.

\subsubsection{Fluid arrangement in the pore space}

A visual inspection of the greyscale images acquired after waterflooding for the two samples shows that the fluid arrangement differs. While in the unaltered sample, clay minerals are mainly filled with brine after the waterflooding, in the altered sample, brine is prevented from invading the small pores of the clay (Figure 2). Since clay aggregates mainly expose their surfaces to small pores, if clay minerals were still preferentially waterwetting we would expect brine to imbibe easily within these pores. On the contrary, the qualitative observation that these clay aggregates are mainly filled with oil suggests they have altered to an oil-wet state.

As shown for Bentheimer sandstone, we expect oil-coated surface area fraction to be positively correlated with oil saturation, i.e. the more oil in the pore space, the larger the fraction of mineral surface area contacted by oil. However, for both Berea Unaltered and Berea Altered this correlation is weak, as a consequence of the narrow range of fluid saturation in the experiment. 


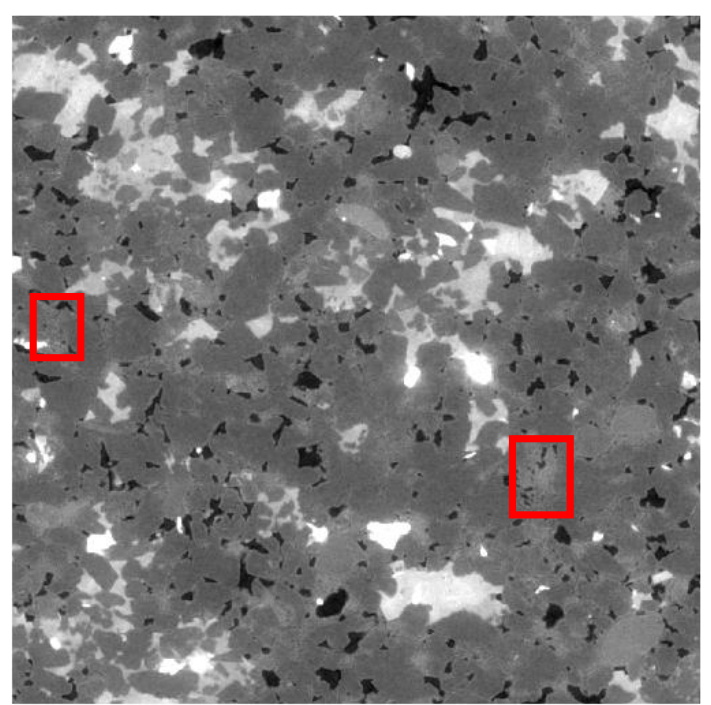

a)

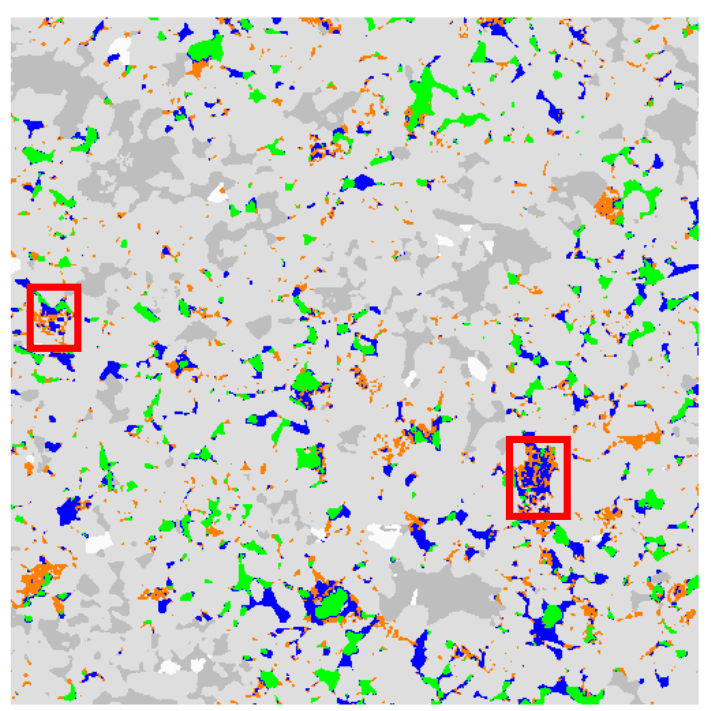

c)

\begin{tabular}{|c|c|}
\hline Quartz-feldspar & Clay \\
\hline Calcite & Brine phase \\
\hline Others & Oil phase \\
\hline
\end{tabular}

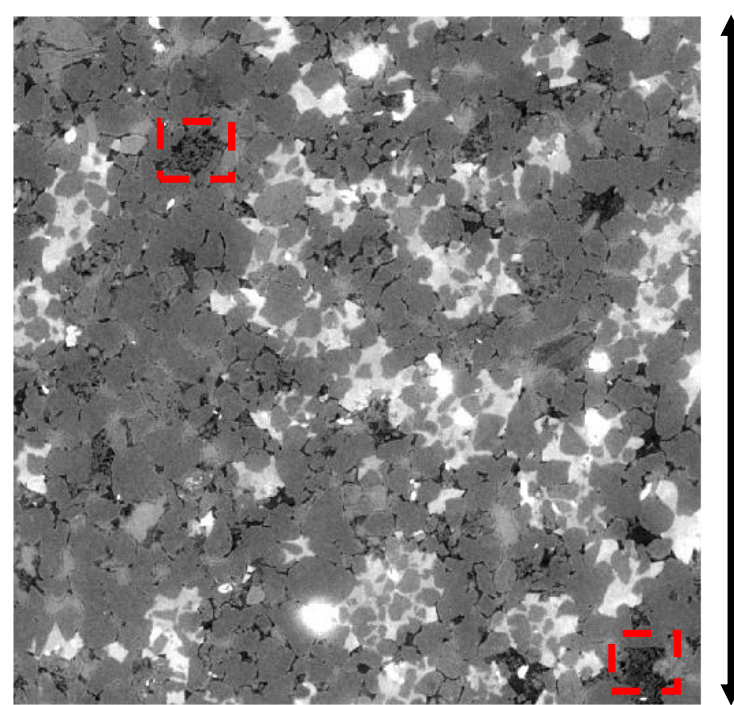

b)

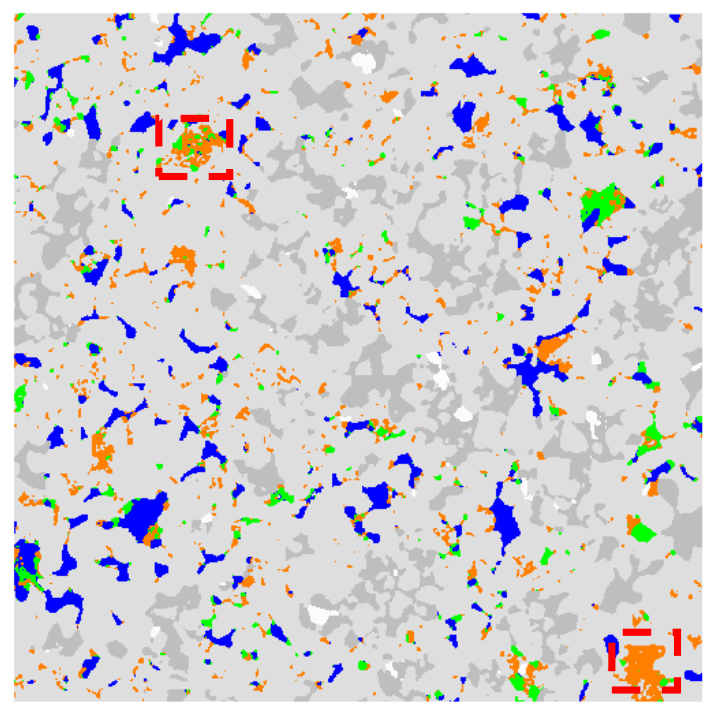

d)

Figure 2. a) and b) show the greyscale images acquired after waterflooding of Berea Unaltered and Berea Altered, respectively (in the Supporting Information the respective dry scans can be found, Figure S1). c) and d) show the segmented respective of a) and b). a) and b) show the change in clay wetting preference due to the effectiveness of the ageing protocol in Berea Unaltered and Berea Altered, respectively. In the sample Berea Unaltered clay aggregates are readily invaded by brine during waterflooding. In contrast, in the aged sample Berea Altered, brine invasion is largely prevented by the oil-wetting behaviour of clay surfaces. 
The oil-coated surface area fractions computed for Berea Unaltered suggest that all mineral groups considered are preferentially wetting to brine (Figure 3). Average oilcoated surfaces are always less than water coated surfaces even at high oil saturation. The average oil-coated clay surface area fraction is smaller than the quartz-feldspar fraction and this may be due to pore morphology and/or sub-resolution roughness. The small pores found in these clays are preferentially imbibed by brine, due to the high capillary pressure required for the non-wetting phase to occupy them. Similarly, calcite cement mainly exposes its surface area to brine. This is a consequence of the capillary pressures associated with the narrow pore regions that the cementation did not fill when it formed (Figure 2). These findings are consistent with previous studies identifying these minerals as water-wet under experimental conditions similar to what we used (Blunt et al., 2019; Khishvand et al., 2016; Singh et al., 2016). In the unaltered sample pore geometry and rock texture are likely to be responsible for the differences in the oil-coated mineral surface area fractions encountered. The system is uniformly water-wet.

In contrast, rock mineral heterogeneities do control wettability alteration during the ageing procedure. In Berea Altered, with a remaining oil saturation of $24 \%, 54 \%$ of the clay surface area is coated by oil. This shows a strong change in the wetting preference of clay minerals, from water-wet to oil-wet. Even at lower oil saturation, there is much higher surface area coverage of clay minerals by oil in the altered sample relative to the unaltered sample. Similarly, a large increase is observed for cemented calcite, when results for Berea Unaltered are compared to those obtained for Berea Altered. On the other hand, quartz and feldspar do not show as strong of a wettability change. The reduced activity of quartz and feldspar surfaces during ageing compared to those of clay and calcite is consistent with what has been observed in Alipour Tabrizy et al. (2011), where pure powdered kaolinite and calcite were found more prone to wettability alteration.

\section{Conclusions}

The analysis of rock mineral surface coverage by fluids can depict differences in the wetting state of two fluid-phase systems. The solid surface covered by a fluid is positively correlated with the saturation of that fluid. The particular relationship between fluid saturation and fluid-mineral interfacial area depends on the wetting state of the system. Considering the case of a uniformly water-wet system, we proposed a model that relates rock coverage to fluid saturation, fluid-fluid interfacial curvature and fluid-fluid interface extent, measurements more easily acquired with X-ray micro-CT imagery than alternative approaches to in situ wetting characterization, e.g., contact angle. This model was validated by observations made before and after wetting alteration on a mineralogically homogeneous Bentheimer sandstone.

The measure of rock surface coverage allowed us to investigate the role that mineralogy plays in defining the wetting state of two sandstone rocks. In an untreated rock sample with significant fractions of quartz, calcite, kaolinite and feldspar, fluid arrangement and surface coverage after a drainage and imbibition displacement sequence were consistent with a uniformly water-wet rock, regardless of local mineralogy. However, in a sample previously exposed to crude oil at a temperature of $80^{\circ} \mathrm{C}$ for 30 days, mineralogical heterogeneity has been found responsible for heterogeneous wettability alteration processes. Clay and calcite minerals were found more readily altered to an oil-wet state than quartz and feldspar minerals. As a consequence, the sample wetting state was heterogeneous, mixed-wet, with the distribution of the wetting state controlled by the local mineralogy. 


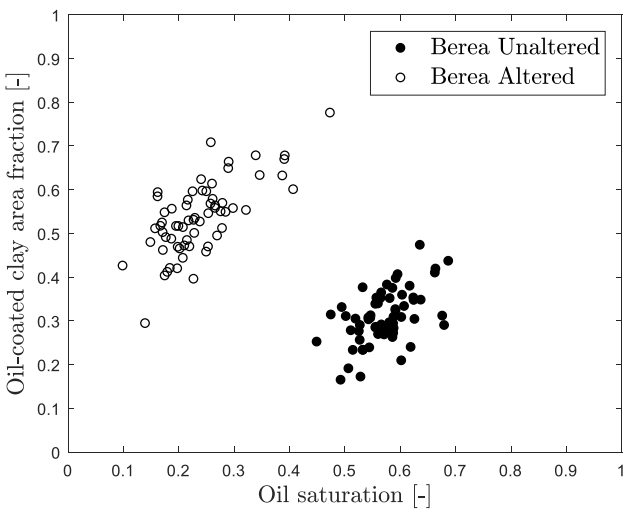

a)

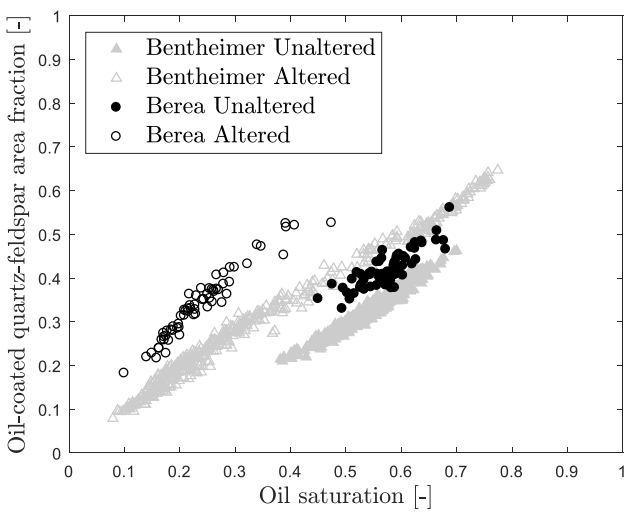

b)

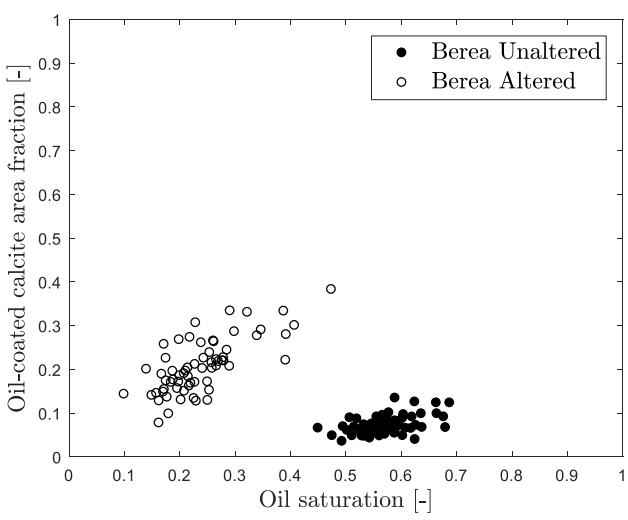

c)

Figure 3. Oil-coated area fractions $\left(a_{i j}\right)$ computed in the two Berea sandstone samples imaged after waterflooding. The average remaining oil saturation in Berea Unaltered is $57 \%$. The average remaining oil saturation in Berea Altered is $24 \%$. Quartz and feldspar minerals show a modest shift towards oil wetting. By comparison, clay and calcite minerals preferentially altered to an oil-wet state, with an average increase in the oil-coated area fraction of $74 \%$ and $184 \%$, respectively. For the average and standard deviation values of the oil-coated area fractions $\left(a_{i j}\right)$ see Table S2 in the Supporting Information. For reference, b) also reports the oil-coated area fractions $\left(a_{i j}\right)$ computed for the two Bentheimer samples in b), being Benthimer mainly constistuted by quartz. 


\section{Acknowledgments}

We gratefully acknowledge Shell Global Solutions International B.V. for permission to publish this work. The Unaltered Bentheimer sandstone data are available from Lin et al. (2018b). The Altered Bentheimer sandstone dataset are available from Lin et al. (2020). The Berea sandstone datasets are available from Garfi et al. (2020).

\section{References}

Alhammadi, A. M., AlRatrout, A., Singh, K., Bijeljic, B., \& Blunt, M. J. In situ characterization of mixed-wettability in areservoir rock at subsurface conditions. Scientific Reports, 7(1), 10753. Retrieved from http://www . nature.com/articles/s41598-017-10992-w doi: 10.1038/ s41598-017-10992-w

Alipour Tabrizy, V., Denoyel, R., \& Hamouda, A. A. (2011). Characterization of wettability alteration of calcite, quartz and kaolinite: Surface energy analysis. Colloids and Surfaces A: Physicochemical and Engineering Aspects, 384(1-3), 98-108. Retrieved from http://dx.doi.org/10.1016/ j.colsurfa.2011.03.021 doi: 10.1016/j.colsurfa.2011.03.021

AlRatrout, A., Raeini, A. Q., Bijeljic, B., \& Blunt, M. J. (2017). Automatic measurement of contact angle in pore-space images. Advances in Water Resources, 109, 158-169. doi: 10.1016/j.advwatres.2017.07.018

Anderson, W. (1987a). Wettability Literature Survey- Part 4: Effects of Wettability on Capillary Pressure. Journal of Petroleum Technology, 39(10), 16051622. doi: $10.2118 / 16471-\mathrm{PA}$

Anderson, W. (1987b). Wettability Literature Survey-Part 5: The Effects of Wettability on Relative Permeability. Journal of Petroleum Technology, 39(12), 1605-1622. doi: 10.2118/16471-PA

Andrew, M., Bijeljic, B., \& Blunt, M. J. (2014). Pore-scale contact angle measurements at reservoir conditions using X-ray microtomography. Advances in Water Resources, 68, 24-31. Retrieved from http://dx.doi.org/10.1016/j .advwatres. 2014.02.014 doi: 10.1016/j.advwatres.2014.02.014

Berg, S., Ott, H., Klapp, S. A., Schwing, A., Neiteler, R., Brussee, N., ... Others (2013). Real-time 3D imaging of Haines jumps in porous media flow. Proceedings of the National Academy of Sciences, 110(10), 3755-3759. doi: $10.1073 /$ pnas. 1221373110

Beucher, S., \& Meyer, F. (1993). The morphological approach to segmentation: the watershed transformation. Mathematical Morphology in Image Processing , 433-481. Retrieved from https://www.crcpress.com/Mathematical -Morphology-in-Image-Processing/Dougherty/p/book/9780824787240 doi: ExportDate6May2013

Blunt, M. J., Jackson, M. D., Piri, M., \& Valvatne, P. H. (2002). Detailed physics, predictive capabilities and macroscopic consequences for pore-network models of multiphase flow. Advances in Water Resources, 25(8), 1069-1089.

Blunt, M. J., Lin, Q., Akai, T., \& Bijeljic, B. (2019). A thermodynamically consistent characterization of wettability in porous media using high-resolution imaging. Journal of Colloid and Interface Science, 552, 59-65. Retrieved from http://www . sciencedirect.com/science/article/pii/S0021979719305648 doi: https://doi.org/10.1016/j.jcis.2019.05.026

Bradford, S. A., \& Leij, F. J. (1997). Estimating interfacial areas for multi-fluid soil systems. Journal of Contaminant Hydrology, 27(1), 83-105. Retrieved from http://www. sciencedirect.com/science/article/pii/S0169772296000484 doi: https://doi.org/10.1016/S0169-7722(96)00048-4

Buades, A., Coll, B., Matem, D., Km, C. V., Mallorca, P. D., Morel, J.-m., \& Cachan, E. N. S. (2005). A non-local algorithm for image denoising. (0), $0-5$. 
Buckley, J. S. (1998). Wetting Alteration of Solid Surfaces by Crude Oils and Their Asphaltenes. Revue de l'Institut Français du Pétrole, 53(3), 303-312. doi: 10 $.2516 /$ ogst: 1998026

Buckley, J. S., \& Liu, Y. (1998). Some mechanisms of crude oil/brine/solid interactions. Petroleum Science and Engineering, 155-160.

Buckley, S., \& Leverett, M. (1942). Mechanism of fluid displacements in sands. Transactions of the AIME, 146, 107-116.

Bultreys, T., Boone, M. A., Boone, M. N., De Schryver, T., Masschaele, B., Van Hoorebeke, L., \& Cnudde, V. (2016). Fast laboratory-based micro-computed tomography for pore-scale research: Illustrative experiments and perspectives on the future. Advances in Water Resources, 95, 341-351. Retrieved from http://dx.doi.org/10.1016/j.advwatres.2015.05.012 doi: 10.1016/j.advwatres.2015.05.012

Bultreys, T., De Boever, W., \& Cnudde, V. (2016). Imaging and image-based fluid transport modeling at the pore scale in geological materials: A practical introduction to the current state-of-the-art. Earth-Science Reviews, 155, 93-128. Retrieved from http://dx.doi.org/10.1016/j.earscirev.2016.02.001 doi: 10.1016/j.earscirev.2016.02.001

Coles, M. E., Hazlett, R., Muegge, E., Jones, K., Andrews, B., Dowd, B., ... W.E., S. (1996). Developments in synchrotron x-ray microtomography with applications to flow in porous media. Society of Petroleum Engineers, 1(4), 288-296. doi: $10.2118 / 36531-\mathrm{MS}$

Donaldson, E. C., Thomas, R. D., \& Lorenz, P. B. (1969). Wettability Determination and Its Effect on Recovery Efficiency. SPE Journal, 13-20. doi: 10.2118/ 2338-PA

Garfi, G., John, C. M., Berg, S., \& Krevor, S. (2019, dec). The Sensitivity of Estimates of Multiphase Fluid and Solid Properties of Porous Rocks to Image Processing. Transport in Porous Media. Retrieved from https://doi.org/ 10.1007/s11242-019-01374-z doi: 10.1007/s11242-019-01374-z

Garfi, G., Lin, Q., Berg, S., \& Krevor, S. (2020). Berea sandstone: X-ray microct imaging of waterflooding in a water-wet and a mixed-wet sample. http:// www.digitalrocksportal.org/projects/265. Digital Rocks Portal. doi: 10 .17612/Y7YD-H265

Garing, C., de Chalendar, J. A., Voltolini, M., Ajo-Franklin, J. B., \& Benson, S. M. (2017). Pore-scale capillary pressure analysis using multi-scale X-ray micromotography. Advances in Water Resources, 104, 223-241. Retrieved from http://www.sciencedirect.com/science/article/pii/S0309170816305437 doi: https://doi.org/10.1016/j.advwatres.2017.04.006

Helgeson, H. C., Murphy, M., \& Aagaard, P. E. R. (1984). Thermodynamic and kinetic constraints on reaction rates among minerals and aqueous solutions . II . Rate constants, effective surface area, and the hydrolysis of feldspar. , 48(c), 2405-2432.

Herring, A. L., Middleton, J., Walsh, R., Kingston, A., \& Sheppard, A. (2017). Flow rate impacts on capillary pressure and interface curvature of connected and disconnected fluid phases during multiphase flow in sandstone. Advances in Water Resources, 107, 460-469. Retrieved from http://www.sciencedirect.com/science/article/pii/S0309170816307011 doi: https://doi.org/10.1016/j.advwatres.2017.05.011

Joekar-Niasar, V., \& Hassanizadeh, S. M. (2012, sep). Uniqueness of Specific Interfacial Area-Capillary Pressure-Saturation Relationship Under NonEquilibrium Conditions in Two-Phase Porous Media Flow. Transport in Porous Media,94(2), 465-486. Retrieved from https://doi.org/10.1007/ s11242-012-9958-3 doi: 10.1007/s11242-012-9958-3

Khishvand, M., Alizadeh, A. H., \& Piri, M. (2016). In-situ characterization of wettability and pore-scale displacements during two- and three-phase flow 
in natural porous media. Advances in Water Resources, 97, 279-298. doi: 10.1016/j.advwatres.2016.10.009

Klise, K. A., Moriarty, D., Yoon, H., \& Karpyn, Z. (2016). Automated contact angle estimation for three-dimensional X-ray microtomography data. Advances in Water Resources, 95. doi: 10.1016/j.advwatres.2015.11.006

Lai, P., Moulton, K., \& Krevor, S. (2015). Pore-scale heterogeneity in the mineral distribution and reactive surface area of porous rocks. Chemical Geology, 411(0), 260-273. Retrieved from http://linkinghub.elsevier.com/ retrieve/pii/S0009254115003290 doi: 10.1016/j.chemgeo.2015.07.010

Lin, Q., Bijeljic, B., Berg, S., Pini, R., Blunt, M., \& Krevor, S. (2020). Pore-scale imaging of multiphase flow at steady state for a mixed-wet bentheimer sandstone. http://www.digitalrocksportal.org/projects/263. Digital Rocks Portal. doi: 10.17612/5WAP-ZM63

Lin, Q., Bijeljic, B., Berg, S., Pini, R., Blunt, M. J., \& Krevor, S. $\quad$ (2019, Jun). Minimal surfaces in porous media: Pore-scale imaging of multiphase flow in an altered-wettability bentheimer sandstone. Phys. Rev. E, 99, 063105. Retrieved from https://link.aps.org/doi/10.1103/PhysRevE.99.063105 doi: 10.1103/PhysRevE.99.063105

Lin, Q., Bijeljic, B., Krevor, S. C., Blunt, M. J., Rücker, M., Berg, S., ... Wilson, O. B. (2019). A New Waterflood Initialization Protocol With Wettability Alteration for Pore-Scale Multiphase Flow Experiments. Petrophysics, 60(02), 264-272. Retrieved from https://doi.org/ doi: 10.30632/PJV60N2-2019a4

Lin, Q., Bijeljic, B., Pini, R., Blunt, M., \& Krevor, S. （2018b). Pore-scale imaging of multiphase flow at steady state for a bentheimer sandstone. http://www .digitalrocksportal.org/projects/157. Digital Rocks Portal. doi: 10 .17612/P7167R

Lin, Q., Bijeljic, B., Pini, R., Blunt, M. J., \& Krevor, S. (2018a). Imaging and Measurement of Pore-Scale Interfacial Curvature to Determine Capillary Pressure Simultaneously With Relative Permeability. , 7046-7060. doi: 10.1029/2018WR023214

Morrow, N. R., \& Szabo, J. O. (1970). Physics and Thermodynamics of Capillary. Industrial and Engineering Chemistry, 62 (6), 32-56. doi: 10.1021/ie50726a006

Porter, M. L., Schaap, M. G., \& Wildenschild, D. (2009). Lattice-Boltzmann simulations of the capillary pressuresaturationinterfacial area relationship for porous media. Advances in Water Resources, 32(11), 1632-1640. Retrieved from http://www.sciencedirect.com/science/article/pii/S0309170809001328 doi: $10.1016 /$ j.advwatres.2009.08.009

Raeesi, B., Morrow, N., \& Mason, G. (2014). Capillary pressure hysteresis behaviour of three sandstones measured with a multistep outflow-inflow apparatus. $\quad \mathrm{Va}$ dose Zone Journal, 13(3). doi: 10.2136/vzj2013.06.0097

Rücker, M., Bartels, W. B., Singh, K., Brussee, N., Coorn, A., van der Linde, H. A., ... Berg, S. (2019). The Effect of Mixed Wettability on Pore-Scale Flow Regimes Based on a Flooding Experiment in Ketton Limestone. Geophysical Research Letters, 46(6), 3225-3234. doi: 10.1029/2018GL081784

Salathiel, R. (1973). Oil recovery by surface film drainage in mixed-wettability rocks. Petroleum Technology, 25, 1216-1224. doi: 10.2118/4104-PA

Scanziani, A., Singh, K., Blunt, M. J., \& Guadagnini, A. (2017). Automatic method for estimation of in situ effective contact angle from X-ray micro tomography images of two-phase flow in porous media. Journal of Colloid and Interface Science, 496, 51-59. Retrieved from http://dx.doi.org/10.1016/ j.jcis.2017.02.005 doi: 10.1016/j.jcis.2017.02.005

Singh, K., Bijeljic, B., \& Blunt, M. (2016). Imaging of oil layers, curvature, and contact angle in a mixed-wet and a water-wet carbonate rock. Water Resource Research, 52, 1716-1728. doi: 10.1002/2015WR018072 
White, A. F., \& Peterson, M. L. (1990). Role of Reactive-Surface-Area Characterization in Geochemical Kinetic Models.

Zou, S., Armstrong, R. T., Arns, J.-Y., Arns, C., \& Hussain, F. $\quad$ (2018). $\quad$ Experimental and Theoretical Evidence for Increased Ganglion Dynamics During Fractional Flow in Mixed-Wet Porous Media.

Water Resources Research, 3277-3289. doi: 10.1029/2017WR022433 